\title{
Los impuestos a puertas, ventanas, perros, caballos y carros de Santa Anna, $1853-1855^{*}$
}

\section{Santa Anna's Taxes on Doors, Windows, Dogs, Horses and Cars, 1853-1855}

\author{
Héctor Strobel del Moral ** \\ (D) https://orcid.org/0000-0001-5790-6610 \\ El Colegio de México, México \\ hstrobel@colmex.mx
}

Resumen: Este artículo trata sobre los impuestos a puertas, ventanas y perros, decretados por Santa Anna entre 1853 y 1854, así como los de caballos y carros, que datan de antes. Pese a lo que la historiografía liberal sostuvo para desprestigiar a Santa Anna, en su tiempo, estas contribuciones no fueron consideradas "extravagantes" ni "ridículas", ya que se adoptaron de Europa y fueron un intento por gravar progresivamente la riqueza sin afectar a las clases menesterosas. Tampoco hay prueba de que se creyeran "odiosas" ni "vejatorias", pues pocos las pagaron y se otorgaron bastantes exenciones. Antes bien, su mala planificación y la concesión de exenciones causó que, a costa de grandes esfuerzos y gastos, lo recaudado fuera poco. Con tal de ahorrar y comenzar el cobro lo más pronto posible, fueron mal planificadas, lo cual perjudicó al

* Agradezco las sugerencias de la doctora Graciela Márquez Colín y del maestro Adrián Meza Holguín. A ambos dedico este artículo.

* Maestro en Ciencias Sociales, maestro en Historia, actualmente realiza su tesis de doctorado en Historia en El Colegio de México.

Cómo citAR: Strobel del Moral, H. (2020). Los impuestos a puertas, ventanas, perros, caballos y carros de Santa Anna, 1853-1855. Secuencia (106), e1704. Dor: https://doi.org/10.18234/secuencia.v0i106.1704

cc (1) Esta obra está protegida bajo una Licencia Creative Commons Atribución-NoComercial 4.0 Internacional. 
erario y dificultó la recaudación. Los funcionarios públicos fueron sus principales críticos y el mismo gobierno decidió abolirlas en 1855 .

Palabras clave: impuesto a puertas y ventanas; impuesto a perros; impuesto a objetos de lujo; Hacienda; Antonio López de Santa Anna.

Abstract: This article deals with the taxes on doors, windows and dogs, decreed by Santa Anna between 1853 and 1854, as well as those on horses and carriages, dating from before. Despite what liberal historiography contended to discredit Santa Anna, at the time, these contributions were not considered "extravagant" or "ridiculous", since they were adopted from Europe and were an attempt to gradually tax wealth without affecting the underprivileged social classes. Nor is there proof that they were regarded as "hateful" or "vexatious", because very few paid them and several exemptions were granted. On the contrary, their poor planning and the granting of exemptions meant that, despite the enormous effort and expense involved, only a small amount was raised. In order to save and begin charging taxes as soon as possible, they were poorly planned, which hurt the treasury and hampered collection. Public officials were its main critics and the government itself decided to abolish them in 1855.

Key words: door and window tax; dog tax; luxury tax; Treasury; Antonio López de Santa Anna.

Recibido: 16 de enero de 2019 Aceptado: 11 de marzo de 2019

Publicado: 6 de noviembre de 2019

\section{INTRODUCCIÓN}

Tos impuestos a puertas, ventanas, perros, carros y caballos del último

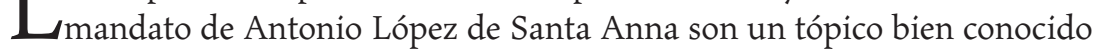
de la historia de México. Han sido divulgados ampliamente por la enseñanza media y superior $y$, en general, el mundo académico tiene noción de su existencia. Sin embargo, más allá de lo superficial, es poco lo que se sabe de ellos, lo cual ha propiciado que a la fecha se les descalifique. El propósito de este 
trabajo es descubrir por qué son juzgados negativamente y explicar la lógica de su adopción y naturaleza, así como los problemas y debates suscitados por su puesta en práctica. La contribución a puertas y ventanas se decretó en enero de 1854. El gobierno se encargó de cobrarla en todo el país y su propósito fue recaudar lo suficiente para sostener un ejército numeroso. Debido a sus complejidades, se analizará este gravamen más a fondo que los demás. El impuesto a perros se promulgó meses antes, por la Ley del 3 octubre de 1853, pero únicamente se autorizó recaudarlo al Ayuntamiento de la Ciudad de México. La misma ley reglamentó la contribución municipal a caballos y coches de uso privado y de alquiler de todo el país, cobrados desde la colonia.

Este artículo comenzará con una exposición sobre la razón por la cual estos impuestos han sido banalizados y puestos en ridículo por la historiografía. Para ello, se realizará un análisis de la prensa, de los testimonios de la época y de las publicaciones históricas de la segunda mitad del siglo XIX y de gran parte del xx. Posteriormente, se explicarán los orígenes europeos del impuesto a puertas y ventanas, así como su lógica y los motivos de su adopción en México. Se intentará comprender su diseño, los problemas que suscitó su recaudación y la conducta del contribuyente. Todo ello a partir de los fondos Hacienda Pública y Contribuciones Directas del Archivo General de la Nación, principalmente. Más adelante, se expondrá la razón de la creación del impuesto a perros y las dificultades que ocasionó, según los informes hallados en el Archivo General de la Nación y en el Archivo Histórico de la Ciudad de México. También se dedicará un apartado a las contribuciones a carros y caballos. Para concluir, se reflexionará en torno a los motivos que llevaron a las autoridades a abolir los impuestos a puertas, ventanas y perros.

\section{HACIA LA CONFORMACIÓN DE UN JUICIO}

Las críticas con las que se han descalificado los impuestos a puertas y ventanas, perros, carros y caballos fueron resultado del éxito de la campaña de desprestigio contra la dictadura de Santa Anna de 1853-1855 en años posteriores a su caída. Cuando fue derrocada, los ataques de la prensa se dirigieron contra la venta de La Mesilla y la ley Lares, que restringió la libre expresión, pero gradualmente se generalizaron a otras disposiciones del gobierno depuesto, hasta acabar por tacharlo de "despótico", "arbitrario" y "corrupto", haciéndolo rayar también en lo "absurdo". Los impuestos que se analizan no fueron cen- 
trales en el debate público a la caída de la dictadura. Tampoco figuraron dentro de la agenda reformista instada por la revolución de Ayutla y la opinión pública. En contraste con el repudio que se les suele atribuir, sorprende su ausencia en las discusiones del momento y en la prensa, que tan hostilmente se comportó contra el gobierno de Santa Anna. Los periodistas no dieron opiniones sobre ellos, ni siquiera el día que fueron abolidos. ${ }^{1} \mathrm{La}$ centralidad del debate y de la crítica periodística en materia hacendaria únicamente giró en torno a los excesivos gastos militares, al "escandaloso despilfarro", al aumento de la deuda pública, al destino de las ganancias por la venta de La Mesilla y a la abolición de la capitación y de los derechos de consumo. ${ }^{2}$

Sólo en una ocasión la prensa dio una opinión sobre estos impuestos, pero englobada al resto de los que se promulgaron entre 1853 y $1855 .{ }^{3}$ La crítica periodística en asuntos fiscales únicamente apuntó que, durante la dictadura, fueron decretados "varios" gravámenes "que pesa[ro]n sobre el país". Sin embargo, no se criticó ninguno en particular, ni mucho menos se les tachó de absurdos. ${ }^{4}$ Guillermo Prieto (1986, pp. 379-385; 1969, pp. 525-550), Manuel Payno (1857, p. 3) y Matías Romero (1870, pp. 383 y 411), tres de los principales ministros de Hacienda de la segunda mitad del siglo xIX que escribieron so-

1 "Contribuciones", El Monitor Republicano, 18 de septiembre de 1855, p. 4; "Contribuciones", El Pata de Cabra, 18 de septiembre de 1855, p. 4; "Consejo del Sr. General en Jefe", El Monitor Republicano, 19 de septiembre de 1855, p. 3; "Contribuciones sobre puertas y ventanas", El Pata de Cabra, 24 de septiembre de 1855, p. 2.

2 Entre otros artículos: "Ramo de Hacienda", El Siglo XIX, 17 de agosto de 1855, p. 4; "Editorial: Legislación del gobierno dictatorial", El Siglo XIX, 31 de agosto de 1855, p. 1; "Editorial: Moralidad de la Revolución, parte 4", El Monitor Republicano, 2 de septiembre de 1855, p. 1; "La administración de Santa-Anna", El Heraldo, 15 de septiembre de 1855, p. 1.

${ }^{3} \mathrm{El}$ autor del artículo escribió las siguientes líneas dentro de una lista de impuestos decretados por Santa Anna: "Hubo [impuestos] sobre todo, sobre luz [haciendo referencia al impuesto sobre puertas y ventanas, también llamado "luces"], sobre la devoción y sobre la alegría, pues el pobre pueblo tenía que pagar por levantar un altar los días de fiestas religiosas y tenía que pagar por bailar. Costaba dinero los pasaportes; los perros estaban sujetos a la capitación y había un impuesto sobre los anuncios que se fijaban en las esquinas". "Parte política: contribuciones”, El Republicano, 21 de septiembre de 1855, p. 1. Cursivas propias. La sátira gira en torno a la cantidad de impuestos decretados y a la exageración de sus atributos.

4 "Editorial: Legislación del gobierno dictatorial", El Siglo XIX, 31 de agosto de 1855, p. 1; "Contribuciones", El Monitor Republicano, 8 de septiembre de 1855, p. 4; "Contribuciones", La Verdad, 11 de septiembre de 1855, p. 2; "Contribuciones", El Monitor Republicano, 17 de septiembre de 1855, p. 3; "Parte política: contribuciones", El Republicano, 21 de septiembre de 1855, p. 1; El Ómnibus, 21 de septiembre de 1855, pp. 2-3; Decreto del gobierno del estado de Zacatecas. Abolición de contribuciones. 24 de agosto de 1855. Fondo Arturo Romo Gutiérrez. Decretos. Caja 13, f. 995. Archivo Histórico del Estado de Zacatecas (en adelante AHEz), México. 
bre las políticas tributarias del último gobierno de Santa Anna, tampoco dejaron opiniones sobre estas contribuciones. ${ }^{5}$ Cabe preguntar, entonces, cómo se originó el discurso fóbico contra ellas si ni siquiera el día que se abolieron, en tiempos de absoluta libertad de opinión, fueron desaprobados.

En 1856, a un año del derrocamiento de Santa Anna, Anselmo de la Portilla, periodista liberal de origen español, publicó su Historia de la revolución de México. En ella, además de narrar la revolución de Ayutla, dedicó un capítulo a criticar la dictadura. Prácticamente ninguno de sus rubros quedó impune. Ocupó varias líneas para repudiar la ley Lares y la venta de La Mesilla. Al referirse a lo fiscal, entre otros asuntos, criticó la cantidad de impuestos que se decretaron y citó a pie de página sólo dos ejemplos de las que llamó "contribuciones insoportables a la propiedad y al trabajo", "ridículas", "extravagantes", "odiosas" y "vejatorias": "La contribución de puertas y ventanas, la de perros y otras, son una prueba bien palpable de lo que aquí se dice" (Portilla, 1856, p. 8).

Estas líneas inauguraron un discurso que, inserto dentro de la historiografía patria, continuó repitiéndose hasta nuestros días. No se sabe si el autor fue el primero en concebir tales argumentos. De cualquier manera, fue el primero en plasmarlos, y al ser su Historia la obra más completa sobre la caída del régimen santannista, continuó siendo citada. ${ }^{6}$ En 1884, Enrique Olavarría, autor del tomo IV de México a través de los siglos, no escatimó tinta al desaprobar el repertorio fiscal de Santa Anna. Repitió los adjetivos que De la Portilla utilizó para referirse a los impuestos que se analizan: "ridículos", "extravagantes", "odiosos" y "vejatorios". Asimismo, agregó otros a la lista: "impracticables" y "monstruosos" (Olavarría, 1988, pp. 815-816 y 841). Sin embargo, Olavarría distinguió que cada una de estas contribuciones era diferente y apuntó más o menos en qué consistieron. Su crítica estaba dirigida al fisco santannista por la cantidad de impuestos que promulgó, de manera que también descalificó otros, como los que gravaban canales, licorerías y puestos fijos y ambulantes.

En los años siguientes, la historiografía liberal no desaprovechó para atacar a la dictadura de Santa Anna. La historiografía patria del siglo xx re-

${ }^{5}$ La opinión de Matías Romero es bastante general. Criticó las "nuevas contribuciones" que decretó Santa Anna, pero en conjunto. Afirmó que fueron "antieconómicas y detestables".

${ }^{6}$ Incluso los conservadores Francisco Arrangoiz o Niceto de Zamacois, aunque no criticaron la política fiscal de la dictadura, admitieron haberla consultado. 
forzó esta idea, antes por considerar "extravagantes" los impuestos analizados que por otra cosa. Algunos autores criticaron el régimen y su Hacienda en general (Romero Flores, 1929, p. 242; Vasconcelos, 1987, p. 138), pero los que se refirieron al tema fiscal no dejaron de revivir una y otra vez la nota al pie de Anselmo de la Portilla, trasladándola de argumento marginal a episodio central de la dictadura (Díaz, 1976, p. 94; Santa-Anna, 1940, p. 178; Toro, 1946, t. III, pp. 506-507). Otros agregaron calificativos nuevos para referirse a los impuestos a puertas y ventanas y a perros, como "insoportables" (Zárate, 1913, p. 223), "absurdos" (López Portillo y Weber, 1959, pp. 126-162; Santa-Anna, 1940, p. 178; Toro, 1946, t. III, pp. 506-507), "impopulares” (Rogelio Álvarez, 1988, t. xII, p. 6884), "locos" (González y González, 1973, p. 112; González y González, 1994, p. 108) e "increíbles e irritadores" (Moreno Paniagua, 2002, p. 96). De un momento a otro, Luis González y González (1973) sumó a la lista de "odiosas y vejatorias gabelas" los impuestos a "caballos y carros", sin explicar en qué consistían o si eran un impuesto o dos. Sin más, los englobó como otra "locura" de Santa Anna (p. 112).

Es sorprendente que argumentos tan subjetivos hayan sobrevivido tanto tiempo y soslayado los enfoques historiográficos actuales. Las historias generales y mínimas de México de El Colegio de México, en sus distintas ediciones y reediciones (Díaz, 1976, p. 94; 1981, p. 828; 1994, p. 828; 2000, p. 589; González y González, 1973, p. 112; 1994, p. 108; Moreno Paniagua, 2002, p. 96), excepto la última (Velásquez García et al., 2014), así como los libros de texto de educación media y superior que tratan el periodo, no dejaron de referirse negativamente a estos impuestos. ${ }^{7}$ Otros autores han sido más precavidos $y$, aunque los mencionan, no emitieron juicios. Algunos prefirieron no abordar el tema al tratar el periodo (Fowler, 2010, p. 376; García Martínez, 1984, p. 134; Lira y Staples, 2014, pp. 443-486). Hasta hoy, la descripción más detallada del impuesto a puertas y ventanas es la de Carmen Vázquez Mantecón (1986). Dedicó un par de páginas de su obra, Santa Anna y la encrucijada del Estado, para explicar las características de estas contribuciones, sucintamente y sin juicios (pp. 113, 139-141).

${ }^{7}$ La crítica permeó incluso a la cultura popular. La película Mexicanos al grito de guerra ocupa varios minutos en parodiar el impuesto (Mexicanos al grito de guerra, dirs. Rodríguez y Gálvez y Fuentes, 1943, mins. 24:40-29:30). 


\section{CON LOS OJOS PUESTOS EN EUROPA: UN INTENTO DE SOLUCIÓN A UN PROBLEMA FISCAL RECURRENTE}

El impuesto a ventanas fue creado a finales del siglo xviI, en la Inglaterra de Guillermo III. Se diseñó como consecuencia de las constantes guerras y del desgaste de las arcas reales (Oates y Schwab, 2015, pp. 163-179). La Corte, interesada en gravar la riqueza de forma directa y progresiva, observó que el número de ventanas de cada casa podía ser proporcional al peculio de su propietario. Los recaudadores no tenían que entrar a las viviendas, sino registrarlas desde el exterior. En 1776, Adam Smith (1814, t. III, p. 303) observó que esto evitaba incomodar a los ciudadanos, al no tener que inspeccionarse sus propiedades ni finanzas, y facilitaba el empadronamiento y la recaudación. Tiempo después, se cobró también por la cantidad de puertas y chimeneas (Scott, 1998, pp. 47-48). En Francia, el impuesto a puertas y ventanas fue decretado en 1798. Su establecimiento tuvo lógica dentro de los ideales de la revolución, por lo equitativas que debían ser las contribuciones. ${ }^{8}$ A lo largo del siglo xix, fue uno de sus pináculos fiscales, suprimido hasta 1925 (Godechot, 1970, pp. 193-195; Scott, 1998, pp. 47-48; Vatus, 1982, p. 50). Durante el siglo xIX, fue implementado también en Suecia, Países Bajos, España y en varias ciudades y reinos alemanes. Bélgica, tras independizarse de Francia, lo siguió recaudando. Si bien la contribución fue fácil de registrar y cobrar, siempre existieron resistencias. Muchas puertas y ventanas se tapiaron y las nuevas viviendas se diseñaron para tener menos (Glantz, 2008, pp. 18-40; Scott, 1998, p. 48).

El 20 de abril de 1853, cuando Santa Anna tomó posesión de la presidencia, las finanzas de México no podían ser peores. Los gastos eran elevadísimos y en su discurso inaugural admitió la "bancarrota completa de la Hacienda pública” (Sierra, 1963, pp. 121-122). La Hacienda mexicana había sufrido severos reveces desde la independencia. En 1853, a cinco años de la guerra contra Estados Unidos, la crisis alcanzó un punto crítico. Para solucionar el problema, el gabinete de la dictadura intentó adoptar la racionalidad fiscal del gobierno francés posrevolucionario. Hasta entonces, los impuestos indirectos, en particular de las aduanas, habían sido el sostén del gobierno mexicano.

${ }^{8}$ Los principales impuestos de Francia en el siglo xix fueron al ingreso de la propiedad, al patrimonio, a la industria y al número de puertas y ventanas de cada casa. Se les llamó "les quatre vieilles", por su larga vigencia. 
Los hacendistas de Santa Anna consideraron riesgoso que las bases fiscales del país descansaran en cimientos tan endebles, razón por la cual reformaron casi todos los ramos de la Hacienda para asentarla en contribuciones directas, como en Francia. Algunos impuestos directos se restablecieron y otros se incrementaron, pero también surgieron nuevos. Gracias a ello, de 1853 a 1855, los ingresos del gobierno aumentaron, pese a que se cargó bastante al contribuyente. El 14 de mayo de 1853 se decretó la centralización de rentas, de forma que los ingresos de los departamentos, como fueron llamados los estados de 1853 a 1855, pasaron a formar parte del erario nacional. ${ }^{9}$

En ese tenor, el 9 de enero de 1854, Santa Anna decretó la contribución a puertas y ventanas. ${ }^{10}$ La supresión del Congreso y la centralización de poderes en el ejecutivo posibilitó que pudiera estipular cualquier impuesto sin debate ni oposición. Fue Ignacio Sierra y Rosso, ministro de Hacienda y consejero de Estado, quien sugirió su adopción. Era xalapeño, al igual que Santa Anna, y había participado con él en 1847 como ministro de Relaciones Exteriores. El impuesto fue denominado "contribución de luces exteriores", pues lo que decía cobrar era el derecho a la luz solar y de farol que ingresaba a las casas. Fue publicado en periódicos, pegado en las calles y difundido en los departamentos. ${ }^{11}$ Según el decreto del 9 de enero, su propósito era gravar la cantidad de puertas de cada casa, incluyendo zaguanes o cocheras, y ventanas o balcones. La tarifa era progresiva y variaba según el sitio de la casa (véase cuadro 1). Una vivienda de la ciudad de México, por ejemplo, pagaba más que cualquier otra del país, y si daba frente a la plaza mayor, pagaba más que las de los suburbios. Según se estipuló, se planeaba que la recaudación fuera mensual y se hiciera sin aumento de empleados ni gastos. Fueron eximidas del pago las casas solariegas "de gentes pobres", las que se hallaran deshabitadas, las del Estado, iglesias, conventos, hospitales, hospicios, escuelas gratuitas y palacios de gobierno, episcopales y municipales. Aunque Sierra y Rosso decretó el impuesto, no pasó un mes antes de que abandonara el ministerio, por lo que su gestión correspondió a sus sucesores, Luis Parres y Manuel Olasagarre. El

${ }^{9}$ Decreto del gobierno. Centralización de las rentas públicas, 14 de mayo de 1853 y Decreto del gobierno. Se restablece la renta de alcabalas, 2 de junio de 1853 (Becerril Hernández, 2013, pp. 37-55; González Navarro, 1983, p. 421; González Prieto, 1994, t. I, pp. 321-322 y 325-326; Jáuregui, 2005, pp. 105-109; Sánchez Santiró, 2009, pp. 257-264).

${ }_{10}$ Decreto del gobierno. Se establece una contribución sobre puertas y ventanas. 9 de enero de 1854 (Dublán y Lozano, 1876, t. viI, pp. 5-6).

${ }_{11}$ “Contribución sobre puertas y ventanas", El Universal, 21 de enero de 1854, p. 1. 


\section{Cuadro 1. Tarifas mensuales del impuesto a puertas y ventanas ${ }^{a}$}

Ciudad de México

Casas que den frente a la plaza mayor

Que den frente a las calles que desembocan a esta

Que den frente a las calles próximas a estas

Todas las demás que cuenten con alumbrado público

Todas las de los suburbios fuera del alumbrado

Capitales de los departamentos

Que den frente a la plaza mayor

0.38

0.25

0.19

0.09

Todas las de los suburbios

0.50

0.38

0.25

0.19

0.13

Que den frente a las calles que desembocan a esta

Que den frente a las calles próximas a estas
Puertas Ventanas

(en pesos) (en pesos)

0.38

0.25

0.19

0.13

0.09

0.25

0.19

0.13

0.06

\section{Ciudades}

Que den frente a la plaza mayor

0.25

0.19

Que den frente a las calles que desembocan a esta

0.19

0.13

Que den frente a las calles próximas a estas

0.13

0.09

Todas las de los suburbios

0.06

0.03

Villas y haciendas

Que den frente a la plaza mayor

0.19

0.13

Que den frente a las calles que desembocan a esta

0.13

0.09

Todas las demás

Pueblos, ranchos y casas solariegas

Casas solariegas y casas que den frente a una plaza mayor

$0.13 \quad 0.06$

Todas las demás

$0.06 \quad 0.03$

Poblaciones y rancherías indígenas

$0.03 \quad 0.02$

a En el México de mediados del siglo xIx, una persona podía cubrir sus necesidades mínimas diarias con uno o dos reales, es decir 0.13-0.26 centavos de peso.

Fuente: "Contribución sobre puertas y ventanas", El Universal, 21 de enero de 1854. 
objetivo del impuesto fue financiar los gastos del Ministerio de Guerra y engrosar las guarniciones departamentales. ${ }^{12}$ El gobierno de Santa Anna buscó respaldarse en las fuerzas armadas. De 1854 a 1855, 94\% de los egresos fueron dirigidos a ese rubro (Tenenbaum, 1985, p. 214).

El decreto del 9 de enero de 1854 fue un intento por emular el sistema hacendario europeo. Otros países latinoamericanos, luego de sus independencias, también pusieron los ojos en los regímenes fiscales de Francia e Inglaterra para sanar sus finanzas y distanciarse del sistema hacendario colonial. Entre otras contribuciones, Brasil, Colombia, Guatemala, El Salvador y México adoptaron en distintos momentos el impuesto a puertas y ventanas. La primera vez que México lo hizo fue de noviembre a diciembre de 1832, por órdenes del presidente Anastasio Bustamante para combatir el Plan de Veracruz. Urgido de recursos, decretó su cobro exclusivo en la ciudad de México. Aunque no todos los contribuyentes pagaron, el impuesto cesó al terminar el conflicto. ${ }^{13}$ En 1843, por disposición del ministro de Hacienda, se elaboró un proyecto de ley para establecer otro impuesto a puertas y ventanas. Este proyecto, sin embargo, jamás se decretó. ${ }^{14}$ Diez años después, el 3 de octubre de 1853, Santa Anna autorizó al Ayuntamiento de la Ciudad de México varios impuestos exclusivos, entre ellos uno por las puertas de cualquier expendio de alcohol, que sobrevivió hasta $1878 .{ }^{15}$ Durante la década de 1870 se cobró también a almacenes de alfombras y tocinerías. ${ }^{16}$

El gran problema del impuesto a puertas y ventanas de enero de 1854 fue que se creó con prisa y sin consultar a nadie. Al no existir Congreso ni

${ }^{12}$ Carta de Ignacio Piquero a Luis Parres. 6 de mayo de 1854. Fondo Hacienda pública. Archivo central. Caja 53, exp. 399, s. f. Archivo General de la Nación (en adelante AGN), México.

${ }_{13}$ Decreto del gobierno. Derogación del impuesto a puertas y ventanas. 29 de diciembre de 1832. Fondo Bandos. Caja 5, exp. 44. Archivo Histórico de la Ciudad de México (en adelante АНСм), México.

${ }^{14}$ Carta de Ignacio Piquero a Manuel Merino. 16 de enero de 1854. Fondo Hacienda pública. Archivo central. Caja 53, exp. 399, s. f. AGN, México.

${ }^{15}$ Para el impuesto a puertas de licorerías (1853-1878) véase "Contribuciones", El Pata de Cabra, 8 de septiembre de 1855, p. 3; Fondo Hacienda. Contribuciones. Vol. 2 023, exp. 306, fs. 1-2. Ансм, México; Fondo Hacienda. Contribuciones. Vol. 2 022, exp. 193, fs. 1-2. Ансм, México; Fondo Hacienda. Contribuciones. Vol. 2 010, exp. 280, fs. 1-2. Ансм, México; Fondo Hacienda. Contribuciones. Vol. 2 023, exp. 391, fs. 1-2. Ансм, México; Fondo Hacienda. Contribuciones. Vol. 2 023, exp. 392, fs. 1-2. АнСм, México.

${ }^{16}$ Para el impuesto a puertas de almacenes de alfombras y tocinerías véase: Fondo Hacienda. Contribuciones. Vol. 2 022, exp. 13, fs. 1-2. Ансм, México; Fondo Hacienda. Contribuciones. Vol. 2 026, exp. 524, fs. 1-2. АнСM, México. 
oposición pública por la censura del régimen, no hubo debate en torno a su establecimiento. Sin embargo, existieron críticas por parte de los funcionarios de Hacienda. Ignacio Piquero y Manuel Merino, jefes de la $3^{\mathrm{a}}$ y $2^{\mathrm{a}}$ dirección general de impuestos, respectivamente, brindaron dictámenes cuando se les solicitaba. Eran funcionarios experimentados, conocedores de los problemas de su ramo y de las resistencias del contribuyente. La opinión de Piquero fue requerida demasiado tarde, a cinco días de publicado el decreto. Sin dudarlo, comunicó que el impuesto debía rediseñarse. Juzgó impreciso que la cuota variara según la zona, pues existía un sinfín de pueblos cuyas calles principales, luego de una cuadra de la plaza mayor, ya eran suburbios. Previno que debía cobrarse al término de cada trimestre y no cada mes por anticipado. De otro modo, el día de pago llegarían multitudes a las oficinas, a las cuales no se podría atender, por lo que serían multadas y volverían al día siguiente a quejarse. Asimismo, resultaría incómodo a los vecinos de las congregaciones viajar cada mes a la oficina recaudadora de las cabeceras. Piquero también aseguró que los empleados tendrían mucho trabajo asentando partidas, expidiendo certificados y contando e inspeccionando la moneda exhibida. Finalmente, anticipó que estas dificultades complicarían la obtención de ganancias, por lo cual sugirió se autorizaran facultades coercitivas contra los que no pagaran y recomendó que no se admitieran exenciones. ${ }^{17}$

El ministro Parres consideró pertinentes algunas sugerencias de Piquero y se alarmó el 31 de enero de 1854, pues al día siguiente debía comenzar la recaudación. Solicitó de inmediato que se suspendiera la ley y se reelaborara con el "detenimiento que se requiere" ${ }^{18}$ Santa Anna se negó, pero concedió un mes de prórroga mientras se preparaba lo necesario. ${ }^{19}$ Pese a que no se reformó el impuesto, la prórroga concedió tiempo a Piquero y Merino para elaborar dos reglamentos y volverlo más operativo. Piquero publicó el suyo el 18 de febrero, el cual ordenaba a cada oficina recaudadora empadronar las casas de su demarcación y registrar la cantidad a recolectar. Para tener un control,

17 Carta de Ignacio Piquero a Manuel Merino. 16 de enero de 1854. Fondo Hacienda pública. Archivo central. Caja 53, exp. 399, s. f. AGN, México.

${ }^{18}$ Carta de Luis Parres a Antonio López de Santa Anna. 31 de enero de 1854. Fondo Hacienda pública. Archivo central. Caja 53, exp. 399, s. f. AGN, México.

${ }^{19}$ Carta de Antonio López de Santa Anna a Luis Parres. 1 de febrero de 1854. Fondo Hacienda pública. Archivo central. Caja 53, exp. 399, s. f. AGN, México; Decreto del gobierno. Prórroga al impuesto de puertas y ventanas. 17 de febrero de 1854. Fondo Bandos. Caja. 24, exp. 20, s. f. Ансм, México. 
ordenó que llevaran un libro de registro de pagos y asignaran a cada contribuyente un folio y una boleta como constancia de liquidación..$^{20} \mathrm{El}$ reglamento de Merino, publicado seis días después, puntualizó varios aspectos del impuesto que necesitaban aclararse: dónde se pagaría, quiénes debían hacerlo, cuándo era válida la exención por casa deshabitada, etc. Además, dispuso que se usaría coerción contra causantes morosos. ${ }^{21}$

Sin atender la sugerencia de Piquero, Santa Anna concedió exenciones al por mayor. Por decreto del 8 de marzo de 1854, eximió toda vivienda de menos de cuatro piezas habitables, las de familias beneficiadas por la Sociedad de San Vicente de Paúl, las de los campesinos anexas a las de sus patrones, $y$ las de vecindades que pagaran menos de 25 pesos de renta mensual. Asimismo, exentó fábricas y trojes. ${ }^{22}$ Sólo días después de la publicación del decreto de exenciones, Santa Anna solicitó la opinión de Piquero, quien se manifestó en contra. Alegó que todos los trabajos de empadronamiento comenzados, que habían costado tanto dinero, serían en vano, pues contemplaban casas ahora eximidas. Previno que estas eran la mayoría del país, por lo que se perdería un ingreso importante que no afectaba mucho a sus propietarios, ya que el impuesto era progresivo. ${ }^{23}$ Santa Anna, sin embargo, no dio marcha atrás e incluso autorizó más exenciones. El gobernador de Yucatán, Rómulo Díaz de la Vega, aseguró que la guerra de Castas imposibilitaría el cobro del impuesto en su departamento, ${ }^{24}$ razón por la cual Santa Anna autorizó eximirlo el 7 de abril de $1854 .{ }^{25}$ Algo similar se concedió a Chihuahua el 2 de mayo, a causa de la guerra contra los apaches. ${ }^{26}$ Pese a todo, Parres comunicó a Merino que los

${ }^{20}$ Instrucciones para la práctica de padrones, exacción y contabilidad de las contribuciones sobre luces exteriores. 18 de febrero de 1854. Fondo Hacienda pública. Archivo central. Caja 521, exp. 1682 , s. f. AGN, México.

${ }^{21}$ Reglamento para la mejor ejecución del decreto de 9 de enero. Fondo Hacienda pública. Archivo central. Caja 521, exp. 1682, s. f. AGN, México.

${ }^{22}$ Decreto del gobierno. Excepciones sobre la contribución de puertas y ventanas. 8 de marzo de 1854, en Dublán y Lozano (1876, t. VII, p. 46).

${ }^{23}$ Carta de Manuel Merino a Luis Parres. 21 de marzo de 1854. Fondo Hacienda pública. Archivo central. Caja 53, exp. 399, s. f. AGN, México.

${ }^{24}$ Carta de Manuel Merino a Luis Parres. 3 de abril de 1854. Fondo Hacienda pública. Archivo central. Caja 53, exp. 399, s. f. AGn, México.

${ }^{25}$ Carta de Luis Parres a Ignacio Aguilar. 7 de abril de 1854. Fondo Hacienda pública. Archivo central. Caja 53, exp. 399, s. f. AGN, México.

${ }^{26}$ Carta de Ángel Frías a Luis Parres. 21 de abril de 1854. Fondo Hacienda pública. Archivo central. Caja 53, exp. 399, s. f. AGN, México; Carta de Luis Parres a Ángel Frías. 2 de mayo de 1854. Fondo Hacienda pública. Archivo central. Caja 53, exp. 399, s. f. AGN, México. 
padrones debían seguir elaborándose como se estipuló, con todo y las casas eximidas, para no tener que invertir en nuevos. ${ }^{27}$

Otro asunto que mermó la recaudación del impuesto fue la autorización a tapiar puertas y ventanas. Todo ocurrió a raíz del decreto del 8 de febrero de 1854 de José Mariano Salas, gobernador del Departamento de México (Estado de México), que prohibió esta práctica. ${ }^{28}$ Esto causó molestia entre los hacendados del actual estado de Morelos, propensos a pagar por las muchas ventanas de sus ingenios. Veintitrés de ellos se quejaron ante el presidente. ${ }^{29}$ Santa Anna ordenó que Salas derogara su decreto y comunicó a los gobernadores que a nadie se le prohibiera tapiar. ${ }^{30}$ El hecho de que algunos individuos tapiaran sus puertas y ventanas sirvió a Olavarría (1988, p. 841) como argumento para criticar la contribución. Según el autor, fue prueba del rechazo al impuesto por parte de la población. Sin embargo, este acto no puede ser interpretado de tal modo, sino como oportunidad para pagar menos. Hubo contribuyentes que, con tal de ahorrar algunos centavos, prefirieron quedarse sin ventanas. ${ }^{31}$

A pesar de que Santa Anna pensó que el impuesto a puertas y ventanas no causaría gastos, fue mucho lo que acabó invirtiendo en él. El 20 de mayo de 1854 tuvo que aumentar el sueldo de los empleados de Hacienda por el trabajo extra que hacían. Piquero advirtió que si no les daba un incentivo dejarían de realizar sus obligaciones. ${ }^{32}$ Asimismo, Santa Anna tuvo que autorizar fuertes sumas en padrones (Olasagarre, 1855, pp. 72-73), mismos que no se terminaron a tiempo, se hicieron mal y retrasaron la recaudación. Pocas poblaciones lograron terminarlos para marzo de 1854. Hacia mediados de mes, el recaudador de contribuciones directas de la ciudad de México comunicó

${ }^{27}$ Carta de Luis Parres a Manuel Merino. 23 de marzo de 1854. Fondo Hacienda pública. Archivo central. Caja 53, exp. 399, s. f. AGN, México.

${ }_{28}$ Decreto del gobierno del Departamento de México. Formación de padrones en el departamento. Fondo Hacienda pública. Archivo central. Caja 53, exp. 399, s. f. AGN, México.

29 Carta de veintitrés propietarios de cañaverales a Antonio López de Santa Anna. Marzo de 1854. Fondo Hacienda pública. Archivo central. Caja 53, exp. 399, s. f. AGN, México.

30 Carta de Luis Parres a José Mariano. 18 de marzo de 1854. Fondo Hacienda pública. Archivo central. Caja 53, exp. 399, s. f. AGN, México; Fondo Hacienda pública. Archivo central. Casa de Moneda. Caja 224, vol. 356, exp. 49, f. 1. AGN, México.

${ }^{31}$ Boletas de la contribución de luces exteriores de San Luis Potosí. 1854. Fondo Hacienda pública. Archivo central. Caja 54, exp. 408, s. f. AGN, México.

32 Carta de Luis Parres a Ignacio Piquero. 20 de mayo de 1854. Fondo Hacienda pública. Archivo central. Caja 53, exp. 399, s. f. AGN, México; Carta de Ignacio Piquero a José Mariano Salas. 19 de mayo de 1854. Fondo Hacienda pública. Archivo central. Caja 53, exp. 399, s. f. AGN, México. 


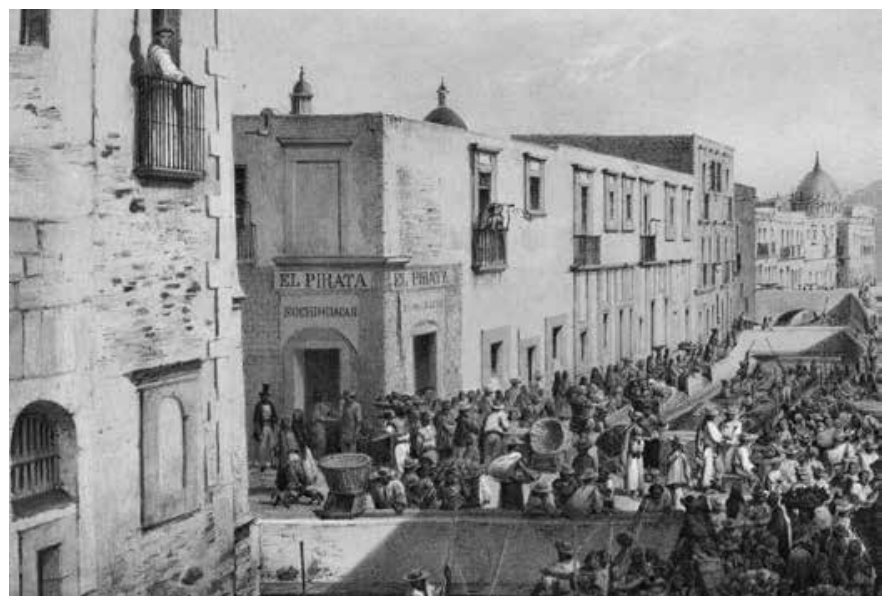

Imagen 1. Calle de Roldán, ciudad de México en 1855. Dos ventanas aparecen tapiadas. Fuente: La Calle de Roldán y su desembarcadero (detalle). Litografía. En Castro, Campillo, Auda y Rodríguez (1855-1856).

a Parres que le resultaba imposible levantar su padrón y expedir cerca de 30000 boletas sin mobiliario ni empleados suficientes. ${ }^{33}$ Algo similar ocurrió en Michoacán, Puebla, Veracruz y en el Departamento de México. ${ }^{34}$ Piquero y Merino sugirieron contratar particulares para elaborar los padrones para no saturar a los empleados de Hacienda. Santa Anna accedió, y el 23 de marzo consintió destinar las cantidades necesarias. Sin embargo, la inversión fue alta. Sólo el padrón del puerto de Veracruz costó 400 pesos. Por si fuera poco, muchos de los padrones que los contratistas entregaron fueron tachados de "inexactos", pues, entre otros factores, incluyeron viviendas exentas. ${ }^{35}$

${ }_{33}$ Carta de Manuel Merino a Luis Parres. 20 de febrero de 1854. Fondo Hacienda pública. Archivo central. Caja 53, exp. 399, s. f. AGN, México; Carta de Manuel Merino a Luis Parres. 16 de marzo de 1854. Fondo Hacienda pública. Archivo central. Caja 53, exp. 399, s. f. AGN, México.

${ }^{34}$ Carta del recaudador general de contribuciones directas de Michoacán a Ignacio Piquero. 23 de febrero de 1854. Fondo Hacienda pública. Archivo central. Caja 53, exp. 399, s. f. AGN, México; Carta de Manuel Merino a Luis Parres. 3 de marzo de 1854. Fondo Hacienda pública. Archivo central. Caja 53, exp. 399, s. f. AGN, México; Carta de Manuel Merino a Luis Parres. 20 de marzo de 1854. Fondo Hacienda pública. Archivo central. Caja 53, exp. 399, s. f. AGN, México.

${ }_{35}$ Carta de Luis Parres a Manuel Merino. 26 de marzo de 1854. Fondo Hacienda pública. Archivo central. Caja 53, exp. 399, s. f. AGN, México. 
Para facilitar la elaboración de un padrón que contemplara el universo rural del departamento de México, José Mariano Salas ordenó el 8 de febrero de 1854 que todo dueño o administrador de fincas tenía cuatro días para dar noticia de la cantidad de puertas y ventanas de sus inmuebles, bajo multa de 10 a 25 pesos por tardanza o engaño. ${ }^{36}$ Sin embargo, estos datos fueron a parar a manos del contratista del padrón del departamento, quien se negó a entregarlo si no se le remuneraba "el asiduo trabajo que impidió su formación" ${ }^{37}$ Parres no autorizó liberar la suma exigida, 150 pesos, sino hasta el 18 de mayo de 1854. Por tal motivo, hasta entonces no se pudo recaudar el impuesto en el departamento. Para junio de 1854 tampoco había podido cobrarse en la ciudad de México ni en los departamentos de Puebla y Michoacán, pues aún no habían elaborado sus padrones y demandaban dinero para hacerlo. ${ }^{38}$

Para mediados de 1854 había sido mínima la recaudación del impuesto y muchos los egresos, todo por no haberse atendido las propuestas de Piquero y Merino desde el inicio. Esto causó que comenzara a ser concebido con frustración por el mismo gobierno. Algunos funcionarios, incluso, propusieron descontinuarlo. En julio de 1854, Santa Anna logró deshacerse de la ardua y costosa recaudación del impuesto a puertas y ventanas de la ciudad de México al traspasarla a su ayuntamiento. La contribución en la ciudad, huelga decir, había rendido muy poco desde su creación. Todos los pagos que no se hicieron de marzo a julio de 1854 fueron condonados por lo difícil que hubiese sido cobrarlos. ${ }^{39}$

${ }^{36}$ Decreto del gobierno del Departamento de México. Formación de padrones en el departamento. Fondo Hacienda pública. Archivo central. Caja 53, exp. 399, s. f. AGN, México.

${ }^{37}$ Carta de José Mariano Salas a Luis Parres. 6 de mayo de 1854. Fondo Hacienda pública. Archivo central. Caja 53, exp. 399, s. f. AGn, México.

${ }^{38}$ Carta de José Mariano Salas a Luis Parres. 6 de mayo de 1854. Fondo Hacienda pública. Archivo central. Caja 53, exp. 399, s. f. AGN, México; Carta de Luis Parres a José Mariano Salas. 18 de mayo de 1854. Fondo Hacienda pública. Archivo central. Caja 53, exp. 399, s. f. AGN, México; Carta de Ignacio Aguilar a Luis Parres. 1 de junio de 1854. Fondo Hacienda pública. Archivo central. Caja 53, exp. 399, s. f. Agn, México; Carta de Luis Parres a Castillo. 8 de junio de 1854. Fondo Hacienda pública. Archivo central. Caja 53, exp. 399, s. f. AGN, México.

${ }^{39}$ Carta de Ignacio Piquero a Manuel Olasagarre. 14 de septiembre de 1854. Fondo Hacienda pública. Archivo central. Caja 53, exp. 399, s. f. AGN, México; Carta de Manuel Olasagarre a Ignacio Piquero. 19 de septiembre de 1854. Fondo Hacienda pública. Archivo central. Caja 53, exp. 399, s. f. AGN, México. 


\section{RECAUDACIÓN Y COMPORTAMIENTO DEL CONTRIBUYENTE: ¿UNA OPINIÓN PÚBLICA NEGATIVA?}

La idea de adoptar el impuesto a puertas y ventanas en México no fue mala. Sin embargo, no se planificó adecuadamente, costó mucho elaborar registros y en poco tiempo no se consiguió generar cultura de pago. Todo ello tuvo efectos importantes en el comportamiento del contribuyente. Para poder analizar la conducta de la fracción que no fue eximida, se utilizará una muestra de boletas de 1854 de la ciudad de San Luis Potosí y su libro auxiliar contable. A diferencia de la mayoría de las ciudades, el padrón de San Luis Potosí se terminó a tiempo, aunque no se sabe si fue de buena calidad. De cualquier manera, y a diferencia de lo que pasó en otras partes del país, para inicios de abril de 1854 el impuesto a puertas y ventanas ya se estaba pagando. Cada contribuyente recibió su folio cotejable con los libros auxiliares, según el reglamento de Piquero. Se puede saber que se expidieron al menos 4257 boletas en 1854, el número de folio más alto que se conserva, aunque el Archivo General de la Nación sólo guarda 46, a lo más el 1.08\% del total. Sin embargo, esta pequeña muestra, que abarca de abril a diciembre de 1854, revela bastante.

El 82\% de la muestra de contribuyentes de San Luis Potosí que pagó el impuesto lo hizo con atraso. Ni siquiera el gobernador, Anastasio Parrodi, lo hizo a tiempo. ${ }^{40}$ A pesar de ello, no se sancionó a nadie. Dividiendo a los contribuyentes en cuatro grupos según la cantidad que pagaron, es posible descubrir qué grupo pagó más, cuál no solía hacerlo y cuánto aportaban porcentualmente. El resultado fue interesante. Como se puede observar en la gráfica 1, los que evadieron el impuesto pertenecían a los grupos que debían contribuir con menos de 80 centavos al mes, mientras que los que cubrieron arriba de 81 centavos siempre pagaron. Los grupos que siempre pagaron estaban formados por propietarios de las casas más grandes de la ciudad, localizadas en el centro o en lugares estratégicos. Las personas que, por su parte, no solían pagar, vivían en inmuebles pequeños, con sólo una puerta y a veces una ventana. No eran considerados "pobres" para eximirles el impuesto, porque sus casas tenían más de tres piezas. Como se puede observar en la gráfica 2 , eran el $80 \%$ de la muestra, aunque sólo aportaron $21 \%$ de lo recaudado. Los

40 Libro auxiliar de cargo para los asientos de la contribución sobre luces exteriores de San Luis Potosí. 1854. Fondo Contribuciones directas. Caja 205, exp. 979.7. AGN, México. 
Gráfica 1. Porcentaje de frecuencia de pago de la muestra de contribuyentes del impuesto a puertas y ventanas, agrupados según la cantidad que cubrían. San Luis Potosí, 1854

120

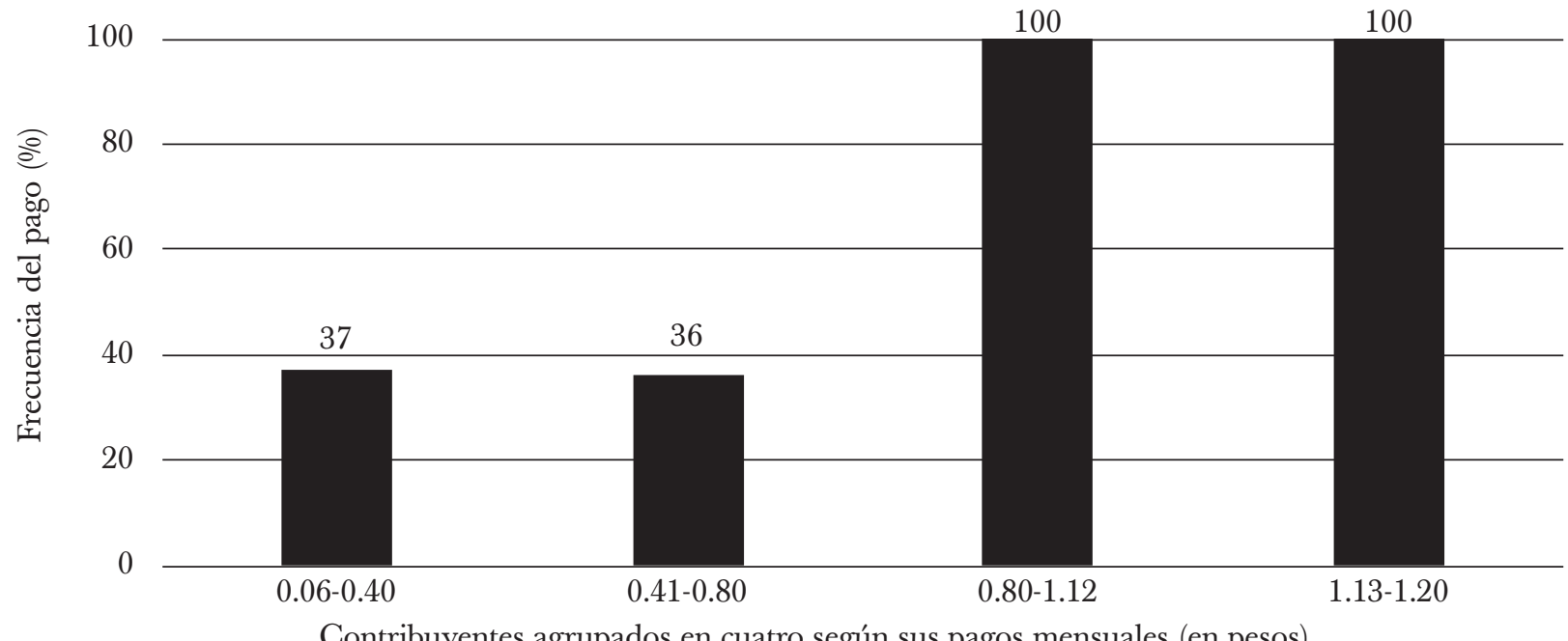

Contribuyentes agrupados en cuatro según sus pagos mensuales (en pesos)

Fuente: elaboración propia a partir de: Boletas de la contribución de luces exteriores de San Luis Potosí. 1854. Fondo Hacienda pública. Archivo central. Caja 54, exp. 408, s. f. AGN, México; Libro auxiliar de cargo para los asientos de la contribución sobre luces exteriores de San Luis Potosí. 1854. Fondo Contribuciones directas. Caja 205, exp. 979.7. AGN, México. 
Gráfica 2. Tamaño porcentual de los grupos de contribuyentes y de sus pagos por el impuesto a puertas y ventanas. San Luis Potosí, 1854

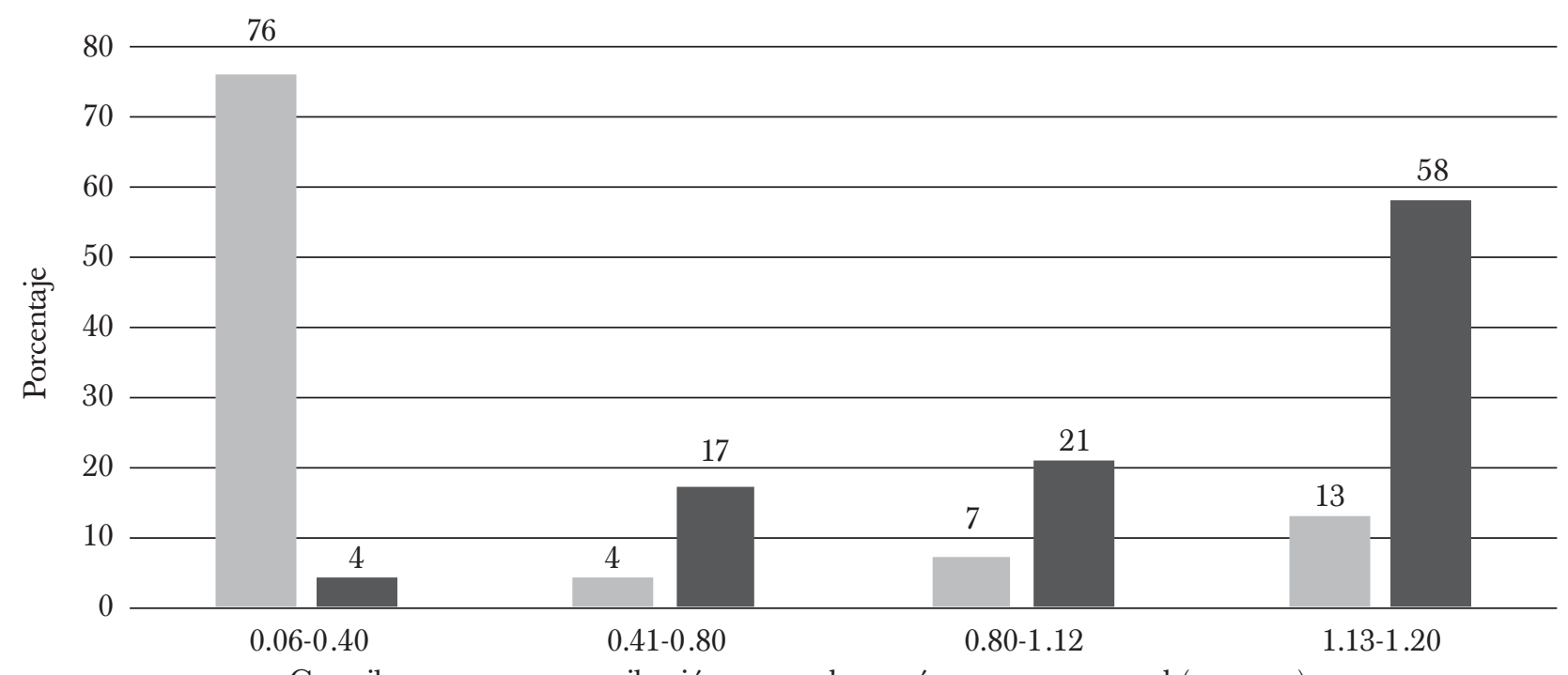

Contribuyentes y su contribución agrupados según su pago mensual (en pesos)

Tamaño de los grupos de contribuyentes

— Tamaño de su contribución en 1854

Fuente: elaboración propia a partir de: Boletas de la contribución de luces exteriores de San Luis Potosí. 1854. Fondo Hacienda pública. Archivo central. Caja 54, exp. 408, s. f. AGN, México; Libro auxiliar de cargo para los asientos de la contribución sobre luces exteriores de San Luis Potosí. 1854. Fondo Contribuciones directas. Caja 205, exp. 979.7. AGN, México. 
otros dos grupos que siempre pagaron, en cambio, aportaron $79 \%$, pese a que sólo eran el $20 \%$ de la muestra.

Aunque para la ciudad de México no se tienen datos detallados, algunas fuentes arrojan indicios de la recaudación y de la conducta de sus contribuyentes. Santa Anna consignó el impuesto a puertas y ventanas al Ayuntamiento de la capital el 6 de julio de 1854. La excusa para cederlo fue que se hizo en remplazo del extinto fondo municipal de pasaportes. ${ }^{41}$ Cuando el Ayuntamiento asumió la recaudación, algunos vecinos se dirigieron a pagar voluntariamente, pero el grueso de la población no. Para poder cobrar, el tesorero municipal, Pedro Solórzano, intentó conseguir un padrón. Como no deseaba gastar en uno, insistió que se le diera el que había formado el gobierno. Piquero se negó, alegando que estaba mal diseñado, elaborado "bajo conceptos absolutamente diversos" sin haber sido "examinado en oficina" e incluía casas eximidas. Insistió que el Ayuntamiento debía elaborar el suyo. A pesar de ello, Olasagarre ordenó que lo entregara, lo cual acató a inicios de diciembre de $1854 .{ }^{42}$ Para entonces, había pasado medio año desde que al Ayuntamiento se le cedió el impuesto, pero no lo había podido cobrar. A sus arcas sólo habían llegado los pagos voluntarios. Solórzano apuntó que, de julio a septiembre de 1854, únicamente había sido pagado lo de 2713 casas. El mismo funcionario mencionó que muchos habitantes alegaban ignorancia o decían estar exentos. ${ }^{43}$ A inicios de 1855, Piquero calculó que la ciudad de México contaba con 8000 viviendas aproximadamente, aunque seguramente casi la mitad quedarían eximidas. Es decir que, para noviembre de 1854, sólo $34 \%$ de los propietarios de la ciudad habían pagado al menos lo de un mes.

Al iniciar el año de 1855 todo cambió. Con padrón en mano, el impuesto ya podía ser cobrado y era posible entregar una boleta a cada contribuyente. El único problema fue que el padrón, en efecto, estaba muy mal elaborado y se perdió mucho tiempo yendo a cobrar a casas eximidas. Para facilitar la recaudación, en enero de 1855, se decretó que en la ciudad de México el im-

${ }^{41}$ Decreto del gobierno. Concesión del impuesto de puertas y ventanas al Ayuntamiento de la Ciudad de México. Fondo Hacienda. Contribuciones. Vol. 2 021, exp. 81, s. f. Ансм, México.

${ }^{42}$ Carta de Ignacio Piquero a Manuel Olasagarre. 2 de diciembre de 1854. Fondo Hacienda pública. Archivo central. Caja 53, exp. 399, s. f. AGN, México.

${ }^{43}$ Carta de Pedro de Solórzano al Ayuntamiento de la Ciudad de México. 18 de julio de 1854. Fondo Hacienda. Contribuciones. Vol. 2 021, exp. 81, s. f. Aнсм, México; Carta de Pedro de Solórzano al Ayuntamiento de la Ciudad de México. 11 de noviembre de 1854 . Fondo Hacienda. Contribuciones. Vol. 2 021, exp. 81, s. f. Ансм, México. 


\section{Cuadro 2. Ingresos del Ayuntamiento de la Ciudad de México en 1855 (en pesos)}

$\begin{array}{lrr}\text { Aduana por derechos municipales } & 170000.00 & 34.92 \% \\ \text { Mercado } & 82000.00 & 16.84 \% \\ \text { Contribución del } 3 \text { al millar sobre fincas } & 73000.00 & 14.99 \% \\ \text { Puertas y ventanas } & 20000.00 & 4.11 \% \\ \text { Coches de providencia } & 4423.33 & 0.91 \% \\ \text { Perros } & 1300.00 & 0.27 \% \\ \text { Carruajes, carros y caballos } & 1127.33 & 0.23 \% \\ \text { Demás propios y arbitrios (25) } & 135006.74 & 27.73 \% \\ \text { Total } & 486857.40 & 100.00 \%\end{array}$

Fuente: ingresos del Ayuntamiento de la Ciudad de México. 1855. Fondo Hacienda. Cortes de caja. Caja 2 005, exp. 23, s. f. Ансм, México.

puesto debía pagarse trimestralmente y se reglamentaron penas por incumplimiento. Con ello, se pusieron en práctica dos de las primeras sugerencias de Piquero. Gracias a ello la recaudación fue superior a la del año anterior, aunque continuó siendo difícil de cobrar. ${ }^{44}$ Resulta complicado saber la cantidad que se obtuvo en la capital, pues la información es escasa. En su declaración, Olasagarre apuntó que no se recaudó nada del impuesto en la ciudad de México antes de julio de 1854, "porque antes de procederse a su cobro se cedió al ayuntamiento". Esto no es creíble, ya que antes de eso hubo contribuyentes que pagaron voluntariamente. Algunos cientos de pesos no figuran entonces en su informe (Olasagarre, 1855, pp. 72-73). ${ }^{45}$ Gracias a los libros de ingresos del Ayuntamiento, se sabe que, de enero a septiembre de 1855, la tesorería mu-

${ }^{44}$ Decreto del gobierno. Regla en el cobro de la contribución de puertas y ventanas de la Ciudad de México. 1 de enero de 1855. Fondo Bandos. Caja 25, exp. 49, s. f. АHCM, México.

${ }^{45}$ Según Tenenbaum (1985), las cifras de Olasagarre en su informe no son confiables, pues, asegura, además de la corrupción de su ministerio, "no tenía que informar a nadie y la administración había perdido todo interés en sus cálculos" (pp. 155-156). Alphonse Dano, secretario de la embajada de Francia en México, lo acusó de enriquecerse a costa del erario. Olasagarre era empleado de Manuel Escandón, el hombre más rico del país, quien lo colocó en el ministerio (Carta de Alphonse Dano a Édouard Drouyn de Lhuys. 25 de enero de 1855. En Díaz, 1963, t. I, p. 162). Sin embargo, Carlos Becerril Hernández (2014) sostiene que Olasagarre se desempeñó con "honradez y transparencia" (p. 214). 
nicipal dijo haber recaudado 20000 pesos por el impuesto a puertas y ventanas, lo cual representó sólo $4.11 \%$ de sus ingresos (véase cuadro 2). Los costos para recaudar esta cantidad, en contraste, fueron muy elevados. En agosto de 1855, cuando Santa Anna abandonó la ciudad, los contribuyentes aprovecharon para dejar de pagar este y todos sus demás impuestos. Sólo se recaudaron 287 pesos, y al mes siguiente, antes de que fuera abolido, 68 pesos. ${ }^{46} \mathrm{Hasta}$ el último momento, mientras se debatía si seguiría vigente, se ordenó al público que siguiera pagándolo. ${ }^{47}$ Sin embargo, pocos hicieron caso y ante las noticias de su posible abolición casi todos dejaron de hacerlo.

Entre otras fuentes que ofrecen indicios sobre la recaudación del impuesto a puertas y ventanas, está el libro de asiento de esta contribución en Tacubaya. Como no es de extrañarse, su padrón se tuvo listo hasta muy tarde, en marzo de 1855. Pese a ello, de marzo a septiembre de ese año, cuando se abolió, sólo siete individuos pagaron el impuesto, todos con atraso. Tacubaya era una villa importante en donde habitaba Santa Anna y se llevaban gran parte de los negocios de la nación (Prieto, 1969, p. 527). Por esta razón sorprende que sólo una cantidad tan pequeña de su población contribuyera. El número más alto de boleta de estas siete es 497, por lo que, cuando mucho, sólo $1.4 \%$ de los propietarios tacubayenses pagó. ${ }^{48}$

No hay noticia de cuánto se recaudó en todo México. Las cuentas de Olasagarre son muy generales. Dan noticia de la recaudación total de cada departamento, pero no desglosan los impuestos de los que se obtuvo. Según Bárbara Tenenbaum (1985), los impuestos portuarios seguían siendo los ingresos más importantes del país, con $47.3 \%$ de lo percibido de 1853 a 1854 . Lo recaudado de las contribuciones directas fue igualmente significativo, 33\%, a diferencia del 5.6 a 2.8\% que se obtuvo de 1848 a 1853 (p. 156). No se puede saber a cuánto equivalía en este 33\% la recaudación del impuesto de luces de cada departamento, pero lo más probable es que haya sido poco. En 1854, en San Luis Potosí sólo se percibieron 1714 pesos. ${ }^{49}$ Las ganancias por este impuesto en zonas afectadas por la revolución de Ayutla, por su parte, fueron

${ }^{46}$ Ingresos del Ayuntamiento de la Ciudad de México. 1855. Fondo Hacienda. Cortes de caja. Caja 2 005, exp. 23, s. f. Ансм, México.

47 "Contribuciones", El Monitor Republicano, 17 de septiembre de 1855, p. 3.

${ }^{48}$ Libro auxiliar de cargo de la contribución de luces exteriores de Tacubaya. 1854-1855. Fondo Hacienda pública. Archivo central. Caja 55, exp. 416. AGN, México.

${ }^{49}$ Libro auxiliar de cargo para los asientos de la contribución sobre luces exteriores de San Luis Potosí. 1854. Fondo Contribuciones directas. Caja. 205, exp. 979.7. AGN, México. 
casi nulas. Por ejemplo, en Guerrero, entre julio de 1853 y octubre de 1854, la recaudación total apenas generó algunos pesos (Olasagarre, 1855, p. 72).

\section{CUANDO "LOS PERROS ESTABAN SUJETOS A LA CAPITACIÓN”: EL IMPUESTO MUNICIPAL A PERROS}

El 3 de octubre de 1853 Santa Anna estableció una contribución por cada perro. Como otras, fue consignada sólo al Ayuntamiento de la Ciudad de México. El impuesto gravó, según el decreto, a todos los que tuvieran perros, "bien para el resguardo de sus casas o intereses, bien para la custodia de los ganados u objetos que se introducen a la municipalidad, bien para la caza o diversión, por gusto o cualquier otro fin".$^{50}$ Sólo fueron eximidos los perros lazarillos. El monto era de un peso mensual por mascota, "sea cual fuese su clase, tamaño o condición" ${ }^{51}$ Sus dueños debían registrarlos hasta ocho días después de publicada la ley, bajo pena de triplicación de cuota. El objetivo de este impuesto también fue gravar la riqueza de los capitalinos. Su problema, al igual que el de puertas y ventanas, fue que no se planificó ni diseñó como debía. Tampoco se hicieron padrones ni se cuidó que se pagara. Todo volvió a recaer en la voluntad del contribuyente. En la actualidad sigue siendo buen indicador de riqueza y en varios países se cobra. Los gobiernos municipales de Alemania, Suiza, Países Bajos, Italia, Irlanda, Australia, Nueva Zelanda y de Quebec, Canadá, se encargan de gravarlo. En Francia existió del siglo xIX a la década de 1970 y en Gran Bretaña fue abolido en 1987 (Salord, 2014).

El Ayuntamiento de la Ciudad de México organizó una comisión que agradeció a Santa Anna por este impuesto. ${ }^{52}$ Sin embargo, fue poco lo que pudo recaudar con él y no llevó a cabo las tareas necesarias para poder cobrarlo. A pesar de que los vecinos tenían ocho días para registrar a sus perros, para finales de octubre de 1853 casi nadie lo había hecho. Pedro Solórzano sugirió solicitar al ministro de Gobernación facultades coercitivas para castigarlos.

\footnotetext{
${ }^{50}$ Decreto del gobierno. Sobre fondos municipales. 3 de octubre de 1853, en Dublán y Lozano (1876, t. vI, pp. 701-708).

${ }^{51}$ El 2 de noviembre de 1853, Santa Anna decretó que el impuesto se reduciría a la mitad. Sin embargo, en la práctica siguió cobrándose lo mismo. Decreto del gobierno. Contribución sobre perros. 2 de noviembre de 1853, en Dublán y Lozano (1876, t. vI, p. 734).

52 Arbitrios municipales. 1853. Fondo Hacienda. Propios y arbitrios. Vol. 2 232, exp. 128, s. f. Ансм, México.
} 
Propuso que se entregaran collares especiales a quienes cubrieran su cuota, para que, si algún perro se descubría sin uno, se capturara y sacrificara al cabo de 24 horas si su dueño no pagaba la contribución pendiente y el recargo. ${ }^{53} \mathrm{La}$ solicitud de Solórzano jamás fue atendida. Por tal motivo, escribió al Ayuntamiento que no se responsabilizaría si se recaudaba poco con "gran perjuicio" a las arcas municipales. Como no se elaboró un padrón del número de perros, los caudales que se recaudaron fueron voluntarios e ínfimos. ${ }^{54}$ En todo 1854 se reunieron 1362 pesos, y de enero a julio de 1855, $1300,{ }^{55}$ cantidad minúscula si se compara con el resto de los ingresos municipales (véase cuadro 2). Cada mes se recaudaba aproximadamente sólo lo de 100 perros, algunos del mismo dueño. La mayoría de los capitalinos evadieron el impuesto y los que lo pagaron casi siempre lo hicieron con atraso. Al igual que otros impuestos, dejó de ser pagado cuando Santa Anna abandonó el gobierno. En agosto de 1855 nadie contribuyó y en septiembre sólo lo hicieron seis personas ${ }^{56}$ (véase imagen 2).

\section{ANTECEDIENDO LA TENENCIA VEHICULAR: LOS IMPUESTOS A CARROS Y CABALLOS}

A diferencia de las contribuciones a puertas y ventanas y a perros, los impuestos a coches y caballos no dieron tantos problemas. Los había de dos tipos: a carros particulares y a carros de alquiler. Hoy en día llamaríamos taxis a estos últimos. No fueron creados por Santa Anna, sino que se adoptaron desde la colonia, también por influencia europea como forma de gravar la riqueza. La historiografía liberal del siglo xIx no los agregó a la lista de contribuciones "odiosas y vejatorias", sino la del xx, y no pudo haberlo hecho, ya que tenían años de ser cobrados y los regímenes liberales lo siguieron haciendo. La única queja en su tiempo fue de Olavarría (1988), pero porque Santa Anna eximió del pago a su propio carro, al del arzobispo y al de ciertos funcionarios (pp. 815-816).

${ }^{53}$ Carta de Pedro Solórzano al Ayuntamiento de la Ciudad de México. 27 de octubre de 1853. Fondo Hacienda. Contribuciones. Vol. 2 021, exp. 74, s. f. АнСм, México.

${ }^{54}$ Carta de Pedro Solórzano al Ayuntamiento de la Ciudad de México. 13 de diciembre de 1853. Fondo Hacienda. Contribuciones. Vol. 2 021, exp. 74, s. f. АнСм, México.

${ }^{55}$ Libro auxiliar por contribuciones del ramo de perros. 1854. Fondo Contribuciones directas. Caja 153, exp. 686. AGN, México.

${ }^{56}$ Ingresos del Ayuntamiento de la Ciudad de México. 1855. Fondo Hacienda. Cortes de caja. Caja. 2 005, exp. 23, s. f. Ансм, México. 

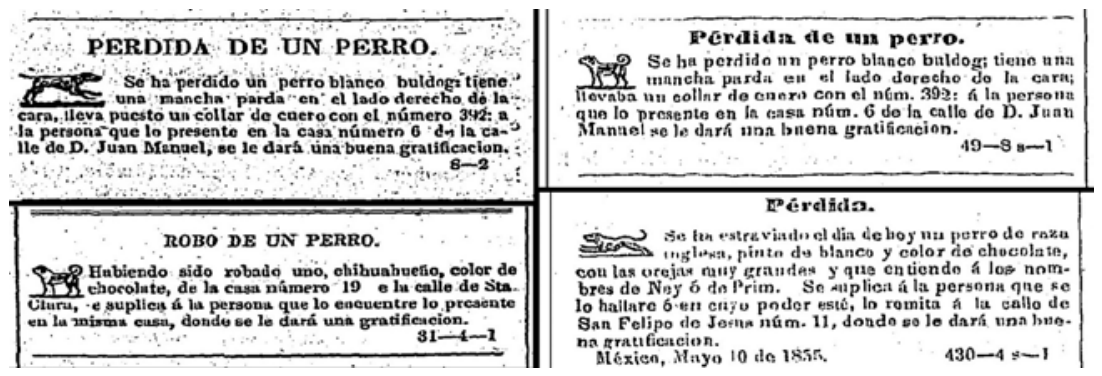

Imagen 2. Anuncios de perros extraviados. Los capitalinos acomodados podían costear perros de raza; algunos extranjeros, anunciar su extravío y pagar rescate. Fuente: "Pérdida de un perro", El Universal, 14 de enero de 1855, f. 4; "Pérdida de un perro", El Siglo XIX, 14 de enero de 1855, f. 4; "Robo de un perro", El Siglo XIX, 16 de enero de 1855, f. 4; "Pérdida", El Universal, 12 de mayo de 1855 , f. 4.

El impuesto a carros de alquiler de la ciudad de México se decretó en 1802 y en años posteriores se generalizó a otros municipios. Para 1825, el derecho por tener un coche de alquiler en la ciudad de México costaba diez pesos mensuales. De 1826 a 1850, este ramo aportó aproximadamente 4.5\% de los ingresos de su Ayuntamiento, con lo cual se reparaba el empedrado (Gamboa Ramírez, 1994, pp. 20-21 y 38-39). ${ }^{57}$ Hacia 1854 había 186 de estos carros en toda la capital. Tenían sitios determinados para estacionarse, como la plaza de Santo Domingo, y se les conocía también como "coches de providencia". La ganancia anual de Cayetano Rubio, su principal concesionario, se estimó en 21500 pesos (Miranda Pacheco, 2011, pp. 218-220; Vázquez Mantecón, 1986, p. 113). El 29 de mayo de 1853, Santa Anna regresó este impuesto al Ayuntamiento, luego de privarlo algún tiempo de él. Sus cuotas se fijaron en el citado decreto del 3 de octubre. Estas podían ir de tres a quince pesos mensuales, dependiendo del tipo de carro. Hacia enero de 1855, Santa Anna transfirió el impuesto a coches de alquiler al Ministerio de Fomento, para gastos de obras públicas. No le fue devuelto al Ayuntamiento sino hasta noviembre de 1855 (véase imagen 3).

El decreto del 29 de mayo de 1853 también facultó al Ayuntamiento para cobrar por carros y caballos particulares, impuesto que igualmente existía desde tiempo atrás bajo la denominación "objetos de lujo". Dicha contribución

${ }^{57}$ El impuesto a carros y caballos también fue utilizado en ocasiones extraordinarias. En 1822, Santa Anna lo decretó en la plaza de Veracruz para expulsar a las tropas españolas de San Juan de Ulúa (Bonilla, 1946, pp. 79-80). 


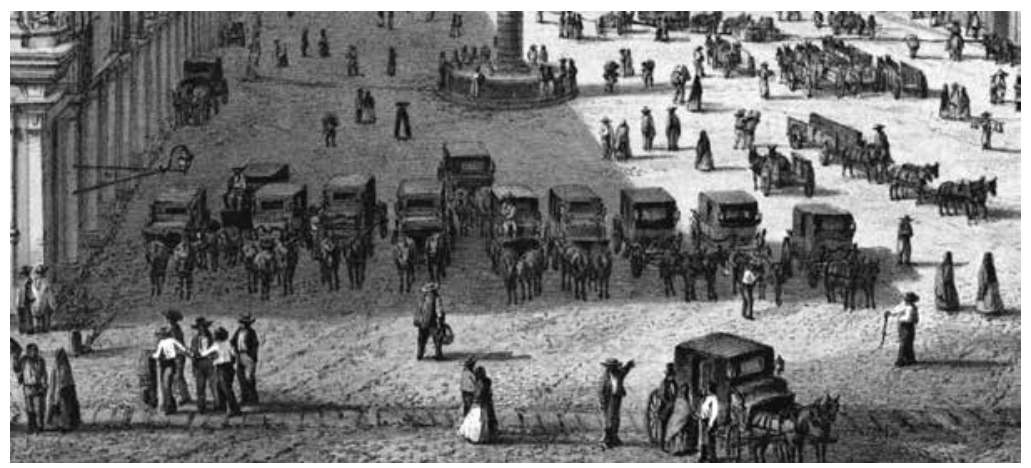

Imagen 3. Sitio de coches de alquiler de la plaza de Santo Domingo en 1855. Fuente: Plaza de Santo Domingo (detalle). Litografía. En C. Castro, J. Campillo, L. Auda y G. Rodríguez (1855-1856).

también la tasaban varios municipios del país y, en cierta forma, persiste en la actualidad como tenencia vehicular. Según la ley del 3 de octubre, se debían sufragar dos pesos y medio por cada carro de dos asientos, cinco pesos por los de cuatro o más, dos por caballo frisón y uno por cualquier otro caballo. A diferencia de las otras contribuciones, esta era trimestral. En promedio, se recaudaba anualmente 7000 pesos por carros y caballos particulares en la ciudad de México. Por algún motivo, en 1855 sólo se recaudaron 1127 pesos $^{58}$ (véase imagen 4).

\section{DEL REPUDIO GUBERNATIVO A LA ABOLICIÓN}

Aunque se logró recaudar algo del impuesto a puertas y ventanas, lo invertido en su cobro fue demasiado. Las expectativas de ganancia habían sido mu-

58 En 1855, la municipalidad de Tacubaya consiguió casi 20 pesos al mes por este ramo, que cobraba a seis individuos, dos de ellos hacendados. Padrón de objetos de lujo de Tacubaya. 1855. Fondo Hacienda pública. Archivo central. Caja 55, exp. 416. AGN, México. En Veracruz la contribución a carros se impuso en 1834, para mantenimiento del empedrado. El ramo generó cerca de 1000 pesos anuales, en concepto de 73 coches. Francisco Fernández al alcalde $1^{\circ}$ de Veracruz. 13 de enero de 1834. Fondo Ayuntamiento. Caja 171, vol. 232, fs. 352-353v. Archivo Histórico Municipal de Veracruz (AhMv), México; Pedro García a Francisco Fernández. 17 de enero de 1834. Fondo Ayuntamiento. Caja 171, vol. 232, fs. 355-355v. AHMv, México. 

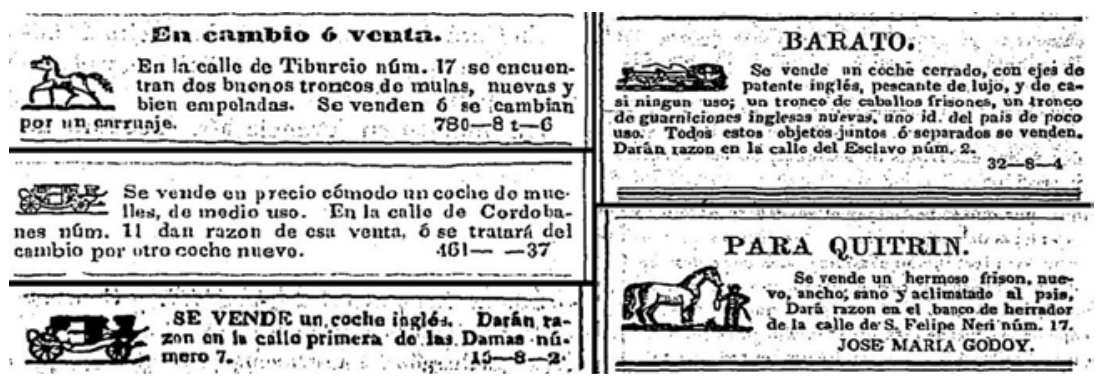

Imagen 4. Anuncios de venta de caballos, mulas y coches. Fuente: El Universal, 4 de agosto de 1854, f. 4; "En cambio o venta", El Universal, 2 de diciembre de 1854, f. 4; "Barato", El Siglo XIX, 29 de enero de 1855, f. 4; "Para quitrín”, El Siglo XIX, 17 de julio de 1855, f. 4.

chas (Olavarría y Ferrari, 1988, p. 841). No se consiguió cumplir su objetivo final: financiar los gastos del ejército, y pese a los préstamos de los agiotistas, el gobierno de Santa Anna no pudo salir de la bancarrota. De la contribución a perros, por su parte, no se obtuvo casi nada. El Ayuntamiento de la Ciudad de México no pudo enmendar sus gastos con él, quedando sus arcas en déficit. Tan dificultosa, costosa y desgastante se tornó la recaudación del impuesto a puertas y ventanas que los departamentos tomaron la iniciativa de suspenderlo en sus demarcaciones cuando Santa Anna abandonó el país. El 24 de agosto de 1855, el gobierno de Zacatecas decretó su abolición, y el 3 de septiembre ocurrió lo propio en Veracruz. ${ }^{59}$ El 17 de septiembre de 1855, el Ayuntamiento de la Ciudad de México solicitó al gobernador interino del distrito, José Vicente Miñón, que lo suprimiera para arreglo de sus finanzas y que, en su lugar, autorizara el cobro por expendio de licores en días festivos. ${ }^{60}$ Tal solicitud fue innecesaria, pues el presidente interino, Rómulo Díaz de la

${ }^{59}$ Pese a que el impuesto a puertas y ventanas era de competencia nacional, el gobierno de Veracruz creyó "de absoluta necesidad" derogarlo en su jurisdicción, debido a que casi todas las poblaciones del estado así lo pedían, pues no producía "provecho alguno para las rentas" y costaba mucho intentar recaudarlo. Manuel Gutiérrez Zamora aseguró que esto a su vez desacreditaba al gobierno y obstaculizaba el cobro de las demás contribuciones. Decreto del gobierno del estado de Zacatecas. Abolición de contribuciones. 24 de agosto de 1855. Fondo Arturo Romo Gutiérrez. Decretos. Caja 13, f. 995. AHEz, México; Gutiérrez Zamora (1986, p. 590); "Contribuciones", El Pata de Cabra, 18 de septiembre de 1855, p. 4.

${ }^{60}$ Sesión de cabildo extraordinario del 17 de septiembre de 1855. Fondo Actas de Cabildo. Libro de 1855. АнСм, México. 
Vega, ya tenía pensado derogarlo, ${ }^{61}$ lo cual hizo el 18 de septiembre de 1855 para toda la república, a un año nueve meses de su creación. ${ }^{62}$ Cuatro días después fueron abolidas también las contribuciones municipales a perros y a carros y caballos particulares. Esta última, sin embargo, se restituyó al poco tiempo, cuando se dotó al Ayuntamiento de nuevos ingresos. ${ }^{63}$

\section{CONCLUSIONES}

Del siglo XIX a la actualidad se han mantenido vivas las mismas críticas sobre los impuestos que se analizaron en este trabajo, resultado del prejuicio que sufrió el gobierno de Santa Anna tras su caída. Estos impuestos se implementaron en un periodo formativo del Estado-nación mexicano. Fueron comunes en su época, cuando gravar progresivamente la riqueza no era sencillo. Santa Anna los adoptó, tal como otros países, en un intento por subsanar la Hacienda nacional. Sin embargo, con tal de ahorrar todo el dinero posible y comenzar pronto la recaudación, sólo logró construir modelos imperfectos, pues los impuestos se planificaron a prisa, perjudicaron el erario y fueron difíciles de cobrar. Al fin y al cabo, fueron los mismos funcionarios públicos quienes decidieron abolirlos y los únicos que se sabe que los criticaron. La experiencia burocrática y el conocimiento en materia de Hacienda de funcionarios como Ignacio Piquero, Manuel Merino y Pedro Solórzano, les permitió advertir las insuficiencias de su diseño. De haber sido escuchados, la historia pudo haber sido otra. Pese a que la implantación de estas contribuciones no fue mala idea, la carga negativa con la que se les asoció causó que no se volvieran a debatir ni adoptar.

No se tiene noticia de que la opinión pública de su tiempo repudiara estos impuestos y no hay nada que haga suponer que los contribuyentes los consideraran "odiosos". La única crítica ciudadana que se conoce fue de algunos

${ }^{61}$ Sesión de cabildo ordinario del 18 de septiembre de 1855. Fondo Actas de Cabildo. Libro de 1855. Ансм, México; "Contribuciones”, El Monitor Republicano, 18 de septiembre de 1855, p. 4.

${ }^{62}$ Decreto del gobierno. Derogación del decreto de puertas y ventanas. 19 de septiembre de 1855. Fondo Bandos. Caja 26, exp. 49, s. f. Ансм, México; “Contribuciones”, El Monitor Republicano, 19 de septiembre de 1855, p. 4; "Contribuciones sobre puertas y ventanas", El Pata de Cabra, 24 de septiembre de 1855, p. 2.

${ }^{63}$ Decreto del gobierno. Derogación de los impuestos a perros, carros y caballos y a imposiciones de dinero. 24 de septiembre de 1855. Fondo Bandos. Caja 26, exp. 58, s. f. Ансм, México. 
propietarios del actual Morelos, pero acabó resuelta a su favor. La queja que surgió en los días posteriores a la caída de la dictadura estuvo dirigida más bien a la cantidad de nuevos impuestos, entre los cuales se encontraban los que se analizaron. Contrario a lo que la historiografía sostiene, tampoco hay registro de que la población los considerara "vejatorios". No se ejerció coerción por la gran cantidad de gente que no contribuía, lo cual provocó un comportamiento variado. Algunos pagaron los impuestos a tiempo, voluntariamente o incluso por adelantado. Otros, en cambio, lo hicieron tarde, incompleto o los evadieron. La inadecuada planificación del impuesto a puertas y ventanas causó un efecto interesante en la conducta del contribuyente. El caso de San Luis Potosí revela que las personas de menos recursos aprovecharon para no pagar. Eran tantos los causantes morosos que resultó imposible castigar a todos. Hubo contribuyentes acomodados que, en cambio, realizaron todos sus pagos. Sumado a ello, decenas de miles de mexicanos fueron eximidos, al exentarse al grueso de la población campesina y urbana. El impuesto tampoco fue cobrado en Yucatán, en gran parte de Chihuahua ni en Guerrero.

\section{LISTA DE REFERENCIAS}

Becerril Hernández, C. de J. (2013). Administrativizar la Hacienda pública. La legislación tributaria del régimen santannista, 1853-1855. Legajos, XVI(2), 35-60.

Becerril Hernández, C. de J. (2014). Manuel Olasagarre. La Hacienda pública ¿bajo las órdenes de Su Alteza Serenísima? En E. Sánchez Santiró (ed.), Pensar la Hacienda pública: personajes, proyectos y contextos en torno al pensamiento fiscal en Nueva España y México (siglos XVIII-Xx) (pp. 189-209). México: Instituto Mora.

Bonilla, J. de D. (1946). Apuntes para la historia de la marina nacional. México: Secretaría de Marina.

Castro, C., Campillo, J., Auda, L. y Rodríguez, G. (1855-1856). México y sus alrededores, colección de monumentos, trajes y paisajes dibujados al natural y litografiados por los artistas mexicanos... México: Establecimiento Litográfico Decaen.

Díaz, L. (comp.) (1963-1967). Versión francesa de México. Informes diplomáticos (Iv tt.). México: El Colegio de México.

Díaz, L. (1976). El liberalismo militante. En D. Cosío Villegas (coord.), Historia general de México (t. III, pp. 85-162). México: El Colegio de México.

Díaz, L. (1981). El liberalismo militante. En D. Cosío Villegas (coord.), Historia general de México. 3a. ed. (t. II, pp. 819-896). México: El Colegio de México. 
Díaz, L. (1994). El liberalismo militante. En D. Cosío Villegas (coord.), Historia general de México. 4a. ed. (t. II, pp. 819-896). México: El Colegio de México.

Díaz, L. (2000). El liberalismo militante. En B. García Martínez et al., Historia general de México: versión 2000 (pp. 583-631). México: El Colegio de México.

Dublán, M. y Lozano, J. M. (comps.) (1876-1912). Legislación mexicana o Colección completa de las disposiciones desde la independencia de la república (xLII tt.). México: Imprenta del Comercio.

Fowler, W. (2010). Santa Anna. Xalapa: Universidad Veracruzana.

Gamboa Ramírez, R. (1994). Las finanzas municipales de la Ciudad de México. 18001850. En R. Hernández Franyuti (comp.), La Ciudad de México en la primera mitad del siglo XIX (t. I, pp. 11-63). México: Instituto Mora.

García Martínez, B. (1984). Historia de México. México: Editorial Éverest Mexicana.

Glantz, A. E. (2008). A tax on light and air: Impact of the window duty on tax administration and architecture, 1696-1851. Penn History Review, xv(2), 18-40.

Godechot, J. (1970). Sens et importance de la transformation des institutions révolutionnaires à l'époque napoléonienne. Annales Historiques de la Révolution Française, XLII(199), 183-202.

González y González, L. (1973). El periodo formativo. En D. Cosío Villegas (coord.), Historia mínima de México (pp. 77-120). México: El Colegio de México.

González y González, L. (1994). El periodo formativo. En D. Cosío Villegas (coord.), Historia mínima de México (pp. 77-120). México: El Colegio de México.

González Navarro, M. (1983). Anatomía del poder en México, 1848-1853. 2a. ed. México: El Colegio de México.

González Prieto, A. (comp.) (1994). Memorias de la Hacienda pública en México, 18211911. 2a. ed. (II tt.). México: Secretaría de Hacienda y Crédito Público.

Gutiérrez Zamora, M. (1986). Memoria leída por el ciudadano Manuel Gutiérrez Zamora, gobernador del Estado libre y soberano de Veracruz, al abrirse las sesiones del honorable congreso el día 21 de junio de 1857. En C. Blázquez Domínguez (comp.), Estado de Veracruz. Informes de sus gobernadores, 1826-1986 (t. II, pp. 589595). Xalapa: Gobierno del Estado de Veracruz.

Jáuregui, L. (2005). Los orígenes de un malestar crónico. Los ingresos y los gastos públicos de México, 1821-1855. En L. Aboites y L. Jáuregui (coords.), Penuria sin fin: historia de los impuestos en México siglos XVIII-XX (pp. 79-114). México: Instituto Mora. Lira, A. y Staples, A. (2014). Del desastre a la reconstrucción republicana, 1848-1876. En E. Velásquez García et al., Nueva historia general de México (pp. 443-486). México: El Colegio de México. 
López Portillo y Weber, J. (1959). Jalisco y el golpe de Estado de Comonfort. En A. Pompa y Pompa et al., La reforma en Jalisco y El Bajío (pp. 126-162). Guadalajara: Librería Font.

Miranda Pacheco, S. (2011). Conflicto político, finanzas federales y municipales en la Ciudad de México, 1846-1855. En C. Marichal y D. Marino (coords.), De colonia a nación: impuestos y política en México (pp. 215-245). México: El Colegio de México.

Moreno Paniagua, A. et al. (2002). Historia de México. México: Santillana.

Oates, W. E. y Schwab, R. M. (2015). The window tax: A case study in excess burden. The Journal of Economic Perspectives, $\operatorname{XxIx(1),~163-179.~}$

Olasagarre, M. (1855). Informe que por orden de Su Alteza Serenísima presenta al supremo gobierno sobre el estado de la Hacienda pública y sus reformas. México: Imprenta de Ignacio Cumplido.

Olavarría y Ferrari, E. (1988). México independiente. En V. Riva Palacio (coord.), México a través de los siglos (t. Iv). México: Editorial Cumbre.

Payno, M. (1857). Memoria de Hacienda presentada al Excmo. Sr. Presidente de la República. México: Imprenta de Ignacio Cumplido.

Portilla, A. de la (1856). Historia de la revolución de México contra la dictadura del general Santa-Anna, 1853-1855. México: Imprenta de Vicente García Torres.

Prieto, G. (1969). Memorias de mis tiempos. México: Editorial Patria.

Prieto, G. (1986). Lecciones de historia patria. México: Instituto Nacional de Bellas Artes.

Rogelio Álvarez, J. (1988). Enciclopedia de México (xIV tt.). México: Secretaría de Educación Pública.

Romero, M. (1870). Memoria de Hacienda y Crédito Público, correspondiente al cuadragésimo quinto año económico. México: Imprenta del Gobierno.

Romero Flores, J. (1929). Historia de la civilización mexicana. México: Compañía Nacional Editora.

Salord, J. (2014). Impôts sur les chiens: ces pays qui taxent les animaux. SantéVet. Le spécialiste de l'assurance santé animale. Recuperado de http://www.santevet.com/articles/impots-sur-les-chiens-ces-pays-qui-taxent-les-animaux\#sthash.s1Xfx1MS. OOcJlwNn.dpbs [Consulta: 10 de enero de 2019].

Sánchez Santiró, E. (2009). Las alcabalas mexicanas, 1821-1857: los dilemas en la construcción de la Hacienda nacional. México: Instituto Mora.

Santa-Anna, A. (1940). Estudio de la historia de México en las escuelas secundarias. México: Editorial Patria.

Scott, J. C. (1998). Seeing like a state: How certain schemes to improve the human condition have failed. New Haven: Yale University. 
Sierra, M. J. (comp.) (1963). General Antonio López de Santa Anna, al jurar como presidente ante el presidente de la Suprema Corte de Justicia el 20 de abril de 1853. En M. J. Sierra (comp.), La Hacienda pública de México a través de los informes presidenciales. 2a. ed. (t. I, pp. 121-124). México: Talleres Gráficos de la Nación.

Smith, A. (1814). An inquiry into the nature and causes of the wealth of nations (III tt.). Edimburgo: Oliphant, Waugh \& Innes.

Tenenbaum, B. A. (1985). México en la época de los agiotistas, 1821-1857. México: Fondo de Cultura Económica.

Toro, A. (1946). Compendio de historia de México (III tt.). México: Editorial Patria.

Vasconcelos, J. (1987). Breve historia de México. México: Fernández Editores.

Vatus, J. (1982). Réflexions actuelles sur les impôts locaux. La Revue Administrative, xxxV(205), 49-51.

Vázquez Mantecón, C. (1986). Santa Anna y la encrucijada del Estado. La Dictadura (1853-1855). México: Fondo de Cultura Económica.

Velásquez García, E. et al. (2014). Nueva historia general de México. México: El Colegio de México.

Zamacois, N. de (1888). Historia de México. Desde sus tiempos más remotos hasta nuestros días (xviII tt.). Barcelona: Imprenta de Juan de la Fuente Parres.

Zárate, J. (1913). Compendio de historia general de México. México: Imprenta de la viuda de Ch. Bouret.

\section{OTRAS FUENTES}

Archivos

AGN Archivo General de la Nación, México.

AHCM Archivo Histórico de la Ciudad de México, México.

AHez Archivo Histórico del Estado de Zacatecas, México.

Ahmv Archivo Histórico Municipal de Veracruz, México.

\section{Bibliografía}

Arrangoiz, F. de P. (1871-1872). Méjico desde 1808 hasta 1867 (IV tt.). Madrid: Imprenta a cargo de D. A. Pérez Dubrul. 
Guevara Sanginés, M. (2002). Nuevas directrices durante los años de la Reforma, 1850-1863. En L. Ludlow (coord.), Los secretarios de Hacienda y sus proyectos (t. I, pp. 307-313). México: Universidad Nacional Autónoma de México.

López de Santa Anna, A. (1974). Mi historia militar y política, 1810-1874. En G. García (comp.), Documentos inéditos o muy raros para la historia de México. 2a. ed. (pp. 5-118). México: Porrúa.

Villegas Revueltas, S. (1997). El liberalismo moderado en México, 1852-1864. México: Universidad Nacional Autónoma de México.

Yáñez Ruiz, M. (1958). El problema fiscal en las distintas etapas de nuestra organización política (vi tt.). México: Talleres de Impresión de Estampillas y Valores.

\section{Filmografía}

Mexicanos al grito de guerra (1943), dirs. Ismael Rodríguez y Álvaro Gálvez y Fuentes. México: Producciones Rodríguez Hermanos.

\section{Hemerografía}

Diario Oficial.

El Heraldo.

El Monitor Republicano.

El Ómnibus.

El Pata de Cabra.

El Republicano.

El Siglo XIX.

El Universal.

La Verdad. 